\title{
Pemenuhan Kebutuhan Oksigenasi Pasien Asthma Bronchiale dengan Teknik Relaksasi Batuk Efektif
}

\author{
Nurleli $^{1, *}$, Ainayya Afninda Utami ${ }^{2}$, Erita Gustina ${ }^{3}$, Suvi Novida $^{4}$ \\ 1,2,3,4 Akademi Keperawatan Kesdam I/Bukit Barisan Medan, Jl. Putri Hijau No. 17, Medan, Indonesia \\ ${ }^{1}$ nurleli@gmail.com*; ${ }^{2}$ ainayya@gmail.com, ${ }^{3}$ erita@yahoo.co.id, ${ }^{4}$ suvi_novida@gmail.com \\ * corresponding author
}

ARTICLE INFO

Article history

29-08-2021

24-09-2021

06-10-2021

Keywords

Bronchial asthma

Need for oxygen

Relaxation

Effective cough

\section{ABSTRACT}

Bronchial asthma is a disease of respiratory tract obstruction caused by muscle contraction, inflammation, and accumulation of secretions around the bronchi. Meeting the need for oxygenation is part of the management of asthmatic bronchial patients. This case study aims to describe the fulfillment of oxygenation needs. The case study method uses a descriptive design with a nursing care approach in the same two cases, namely respondents with bronchial asthma. The case study was conducted at the Putri Hijau Kindergarten II Hospital from October to December 2018. The data collection method was through interviews, physical examinations, supporting examinations, using the assessment format as an instrument in data collection. After intervention with effective cough relaxation techniques as well as collaboration in the administration of drug and oxygen therapy, during four days of treatment, both respondents were able to meet their oxygenation needs optimally. It was concluded that the intervention had an effect on the effectiveness of airway clearance so as to eliminate shortness of breath, based on this study, it is hoped that it can be applied by health workforce.

\section{Pendahuluan}

Asthma merupakan penyakit obstruksi saluran pernafasan yang disebabkan kontraksi otot, inflamasi, dan penumpukan sekret disekitar bronkus. Obstruksi saluran pernafasan merupakan gangguan fisiologis terpenting pada klien asthma yang dapat menghambat aliran udara selama inspirasi dan ekspirasi, sehingga ventilasi paru tidak optimal yang mengakibatkan klien asthma memiliki ketidakmampuan mendasar dalam mencapai angka aliran udara normal selama pernafasan terutama ketika ekspirasi [1].

Berdasarkan surveiGlobal Initiative for Asthma (GINA) memperkirakan bahwa hampir 300 juta orang diseluruh dunia menderita asthma. Pada sepuluh tahun terakhir, telah terjadi peningkatan tajam insiden asthma di Afrika Selatan dan negara-negara di Eropa Timur, termasuk KawasanBaltik, terutama pada anak dan geriatrik. Data ini melakukan para peneliti sebelumnya hipotesis bahwa prevalensi asthma dapat meningkat secara global dengan penambahan 100 juta orang yang didiagnosis asthma pada tahun 2025 [1].

Terjadinya serangan asthma pada manusiadapat disebabkan oleh alergi terhadap sesuatu, seperti udara dingin atau panas, asap, debu dan bulu. Alergi ini biasanya bersifat menurun atau faktor gen. Penyebab lainnya yaitu lingkungan kerja, perubahan cuaca, infeksi saluran nafas serta gangguan emosi [2].

Prevalensi asthma pada negara-negara di Afrika, Amerika Tengah dan Selatan mengalami peningkatan yang signifikan.Peneliti GINA memprediksi bahwa lebih dari 40 juta penduduk di Amerika Selatan dan Tengah menderita asthma. Prevalensi asthma yang tinggi yang telah dilaporkan terjadi di Peru (13\%), Kosta Rika (11,9\%), Brazil (11,4\%), dan Ekuador $(8,2 \%)$. Di Afrika, lebih dari 50 juta penduduk diyakini memiliki asthma. Prevalensi asthma tertinggi di benua ini terdapat di Afrika Selatan $(8,1 \%)$ [3]. Indonesia, berdasarkan World Health Organization 
(WHO) memperkirakan bahwa setelahdilakukan penyesuaian umur dari berbagai penduduk, mengungkapkan bahwa Indonesia berada di urutan ke-19 didunia perihal kematian akibat asthma [4].

Penyakit asthma dapat menimbulkan masalah pada jalan nafas dan menganggu aktivitas seharihari. Seorang akan merasa terganggu apabila melakukan aktivitas yaitu cepat merasakan sesak nafas, frekuensi nafas cepat, mudah lelah, dan sulit untuk bernafas. Pada kasus asthma akan menimbulkan batuk disertai dahak yang berlebih. Apabila dahak tidak segera dikeluarkan maka akan menghambat masuknya oksigen ke saluran pernafasan sehingga kebutuhan oksigen dalam tubuh berkurang. Selain itu juga akan menimbulkan suara nafas tambahan mengi pada saat bernafas. Dahak yang timbul pada jalan nafas apabila tidak segera dikeluarkan juga akan menimbulkan komplikasi yang lebih serius [5].

Dahak merupakan materi yang dikeluarkan dari saluran nafas bawah oleh batuk menurut Ilmu Penyakit Dalam FKUI. Pengeluaran dahak dapat dilakukan dengan membatuk ataupun postural drainase. Pengeluaran dahak dengan membatuk akan lebih mudah dan efektif bila diberikan penguapan atau nebulizer. Batuk efektif merupakan satu upaya untuk mengeluarkan dahak dan menjaga paru-paru agar tetap bersih, di samping dengan memberikan tindakan nebulizer dan postural drainage. Batuk efektif dapat diberikan posisi yang sesuai agar pengeluaran dahak dapat lancar. Batuk efektif yang baik dan benar dapat mempercepat pengeluaran dahak pada pasien dengan gangguan sistem pernafasan [6]. Diharapkan perawat dapat melatih pasien dengan latihan batuk efektif untuk pengeluaran dahak dan mempermudah pasien untuk bernafas.

Menurut data Riset Kesehatan Dasar (Riskesdas) tahun 2013 prevalensi penyakit asthma di Indonesia sebesar $4,5 \%$. Terdapat 18 provinsi yang mempunyai prevalensi penyakit asthma melebihi angka nasional. Dari 18 provinsi tersebut 6 provinsi teratas adalah Sulawesi Tengah $(7,8 \%)$, Nusa Tenggara Timur (7,3\%), Yogyakarta (6,9\%), Sulawesi Selatan $(6,7 \%)$, Kalimantan Selatan $(6,4 \%)$ dan Kalimantan Tengah $(5,7 \%)$. Sedangkan provinsi yang mempunyai prevalensi terendah yaitu Sumatera Utara (2,4\%), Jambi $(2,4 \%)$, Bengkulu $(2,0 \%)$ dan Lampung (1,6\%) [7].

Data dari Rekam Medik di Rumah Sakit Putri Hijau Medan pada tanggal 23 November 2019, jumlah kunjungan klien rawat jalan pada tahun 2019 bulan Januari hingga Oktober sebanyak 448 kunjungan terdiri dari 278 perempuan, 170 laki-laki dan 274 klien dengan kasus baru. Jumlah klien rawat inap pada tahun 2017 sebanyak 39 orang yang terdiri dari 23 laki-laki dan 16 perempuan.

\section{Metode}

Penelitian ini merupakan penelitian deskriptif dengan rancangan studi kasus tujuan untuk mengetahui gambaran pemenuhan kebutuhan oksigenasi pada pasienAsthma Bronchiale di Rumah Sakit TK II Putri Hijau Medan Tahun 2019. Yang menjadi subjek dalam studi kasus ini adalah pasien dengan kasus Asthma Bronchiale yang memiliki masalah dalam pemenuhan kebutuhan oksigenasi dengan dua pasien dalam kasus yang sama dengan kriteria inklusi: pasien Asthma Bronchiale yang dirawat inap di Rumah Sakit Tk II Putri Hijau Medan, penderita asthma bronchiale berjenis kelamin laki-laki atau perempuan, pasien dengan gejala klinis yang mendukung ke arah asthma bronchiale (sesak nafas, sulit bernafas), pasien asthma bronchiale pada dewasa, dan pasien asthma bronchiale yang tersedia menjadi responden. Sedangkan kriteria ekslusi: pasien Asthma Bronchiale yang tidak bersedia untuk dijadikan responden, pasien Asthma Bronchiale pada anak.

Fokus studi dalam penelitian ini yaitu pemenuhan kebutuhan oksigenasi dengan teknik relaksasi batuk efektif pada pasienAsthma Bronchiale dengan dua pasien dalam kasus yang sama. Pengumpulan data diambil dari Rumah Sakit Tk 11 Putri Hijau dengan menggunakan instrumen studi kasus yang meliputi data primer dan data sekunder.Data primer yaitu data yang diambil langsung oleh peneliti menggunakan format pengkajian asuhan keperawatan medikal bedah, yang berisi: identitas diri klien; status kesehatan klien saat ini; pola pemenuhan kehidupan sehari-hari; riwayat keluarga yaitu dengan menggunakan genogram; riwayat lingkungan; status psikologi klien; tingkat perkembangan; karakteristik pemeriksaan fisik.Data sekunder yaitu data yang diambil dari catatan rekam medis pasien berupa catatan hasil pemeriksaan penunjang yang meliputi yaitu: data 
laboratorium, data pemeriksaan diagnostik lain dan terapi medis yang digunakan.

Penyajian data dalam studi kasus ini yaitu dalam bentuk narasi yang digunakan untuk menjelaskan hal-hal yang terkait dengan permasalahan pasien terkait dengan pemenuhan kebutuhan oksigenasi dengan teknik relaksasi batuk efektif pada pasien asthma bronchiale.

\section{Hasil dan Diskusi}

Tabel 1. Identitas Pasien dan Hasil Anamnesa Pasien Asthma Bronchiale

\begin{tabular}{lll}
\hline Identitas Pasien & \multicolumn{1}{c}{ Kasus I } & \multicolumn{1}{c}{ Kasus II } \\
\hline Nama & Ny. L & Ny. N \\
Umur & 41 tahun & 70 tahun \\
Jenis kelamin & Perempuan & Perempuan \\
Agama & Kristen khatolik & Islam \\
Pendidikan & S1 & SD \\
Status perkawinan & Menikah & Menikah \\
Suku & Batak & Melayu \\
Diagnosa medis & Asthma bronchiale & Asthma bronchiale \\
\multicolumn{2}{c}{ 035725 } & 053492 \\
\multicolumn{1}{c}{ No. RM } & 10 Juli 2018 & 18 Juli 2018 \\
Tanggal Pengkajian & & \\
\end{tabular}

Berdasarkan tabel di atas didapatkan dari 2 responden mempunyai diagnosa medis yang sama yaitu Asthma Bronchiale. Pada kasus I berumur 41 tahun sedangkan pada kasus II berumur 70 tahun.

Tabel 2. Keluhan Utama dan Riwayat Sakit

\begin{tabular}{llll}
\hline No. & Data Fokus & Kasus I & Kasus II \\
\hline 1. & Keluhan utama & $\begin{array}{l}\text { Klien mengatakan sesak } \\
\text { nafas, batuk }(+), \text { debu }(+)\end{array}$ & $\begin{array}{l}\text { Klien mengatakan sesak napas saat } \\
\text { beraktivitas, batuk (+), debu (+) }\end{array}$ \\
2. & $\begin{array}{l}\text { Riwayat penyakit } \\
\text { sekarang }\end{array}$ & $\begin{array}{l}\text { Klien mengatakan sesak } \\
\text { nafas semakin berat setiap } \\
\text { kali batuk }\end{array}$ & $\begin{array}{l}\text { Klien mengatakan sesak semakin } \\
\text { berat saat melakukan aktivitas }\end{array}$ \\
3. $\quad \begin{array}{l}\text { Riwayat kesehatan } \\
\text { yang lalu }\end{array}$ & Demam thypoid & Hipertensi \\
4. $\quad$ Riwayat keluarga & Tidak ada & Tidak ada
\end{tabular}

Berdasarkan tabel di atas didapatkan bahwa kasus I dan kasus II memiliki keluhan utama pada kasus I yakni sesak nafas sedangkan pada kasus II mengeluh sesak nafas saat beraktivitas.Kasus I mempunyai riwayat penyakit dahulu demam thypoid sedangkan pada kasus II mempunyai riwayat penyakit hipertensi.

Berdasarkan hasil observasi didapatkan dari 2 responden keadaan umum sama-sama berakral hangat.Kedua responden dalam keadaan compos mentis dengan GCS 4-5-6.Pada pemeriksaan tanda-tanda vital memiliki perbedaan. Pada kasus I tekanan darah: 110/90 mmHg, nadi: $104 \mathrm{x} / \mathrm{I}$, respirasi: $28 \mathrm{x} / \mathrm{I}$, suhu: $36,2^{\circ} \mathrm{C}$ sedangkan pada kasus II tekanan darah $130 / 90 \mathrm{mmHg}$, nadi: $90 \mathrm{x} / \mathrm{I}$, respirasi $30 \mathrm{x} / \mathrm{I}$, dan suhu: $36^{\circ} \mathrm{C}$.

Pemeriksaan fisik kedua responden dimulai dari Breath (B1), kedua responden memiliki bentuk dada simetris. Pada kedua kasus pergerakaan pernafasan thorakal abdominal menggunakan otot bantu pernafasan dan alat bantu pernafasan nasal kanul $3 \mathrm{Lpm}$. Pada kasus I dan kasus II memiliki frekuensi pernafasan melebihi normal yakni pada kasus I sebanyak $28 \mathrm{x} / \mathrm{I}$ dan pada kasus II sebanyak $30 \mathrm{x} / \mathrm{i}$. 
Pemeriksaan fisik pada Blood (B2), pada kedua responden memiliki perbedaan tekanan darah dan nadi. Pada kasus I tekanan darah 110/90 mmHg, nadi 104 x/i sedangkan kasus II 130/90 $\mathrm{mmHg}$, nadi 90 x/i. Kedua responden memiliki capillary refill time $<2$ detik, suara jantung kedua pasien normal (S1 dan S2), akral pada kedua pasien hangat. Pada kedua responden tidak ada terpasang central vien pressure.

Pemeriksaan fisik pada Brain (B3), kedua responden memiliki kesadaran compos mentis dengan GCS 4-5-6.Pada kedua responden tidak ada gangguan pada saraf cranial dan fungsi motorik, fungsi sensorik dalam batas normal. Kedua responden memiliki memori yang dapat mengingat jangka panjang dan pendek. Pemeriksaan fisik pada Bladder (B4), kedua responden tidak ada kelainan pada kandung kemih.Kedua klien tidak terpasang kateter/klien BAK secara spontan.Karakteristik urin pada kedua responden kuning jernih.

Pemeriksaan fisik pada Bowel dan Reproduksi (B5), kedua responden memiliki perbedaan peristaltic, pada kasus I peristaltic usus $12 \mathrm{x} / \mathrm{I}$ sedangkan kasus II peristaltic usus $10 \mathrm{x} / \mathrm{i}$. Pada pemeriksaan abdomen kedua responden tidak ada tanda-tanda ascites serta hepar dan limfa tidak ada nyeri tekan dan pembesaran.

Berdasarkan hasil analisa data di atas bahwa kasus I mengalami masalah keperawatan bersihan jalan nafas tidak efektif berhubungan dengan bronkospasme, edema, hipersekresi mukus yang ditandai dengan keluhan sesak nafas, terpasang $\mathrm{O}_{2}$ nasal kanul $3 \mathrm{Lpm}$, sedangkan pada kasus II mengalami masalah keperawatan bersihan jalan nafas tidak efektif berhubungan dengan bronkospasme, edema, hipersekresi mukus yang ditandai dengan keluhan sesak nafas saat beraktivitas, pemenuhan kebutuhan aktivitas dibantu total dan terpasang $\mathrm{O}_{2}$ nasal kanul $3 \mathrm{Lpm}$.

Berdasarkan Intervensi Keperawatan dari kedua responden mempunyai rencana tindakan keperawatan yang sama tetapi ada satu tindakan yang tidak dilakukan pada kasus I yaitu berikan inj. Dexamethason sesuai indikasi yang diberikan dokter sedangkan pada kasus II berikan inj. Dexamethason sesuai indikasi yang diberikan dokter dikarenakan klien mengalami alergi terhadap obat tersebut.

\section{Kesimpulan}

Didapatkan hasil pengkajian dari kedua responden memiliki beberapa kesamaan yaitu pada penyebab dan faktor pencetus. Adapun perbedaan antara kedua responden meliputi umur yang berbeda, pendidikan yang berbeda, tanda-tanda vital yang berbeda, tindakan yang berbeda dan terapi yang diberikan kepada kedua responden berbeda.

Berdasarkan dari diagnosa keperawatan didapatkan hasil kedua responden memiliki diagnosa keperawatan yang sama yaitu bersihan jalan nafas tidak efektif yang berhubungan dengan bronkospasme, edema mukosa, hipersekresi mukus.

Hasil dari rencana tindakan keperawatan yang telah dilakukan yaitu kedua responden memiliki rencana tindakan yang sama sesuai. Adapun yang perbedaan pada kedua responden yaitu diberikan inj. Dexamethasonsesuai indikasi yang diberikan melalui selang infuse dilakukan pada kasus II dan tidak dilakukan pada kasus I. Tindakan keperawatan yang dilakukan kepada kedua responden sama, sesuai dengan rencana keperawatan. Adapun hal yang membedakan yaitu memberikan inj. Dexamethason sesuai indikasi yang diberikan melalui selang infuse.

Pada hasil evaluasi antara kedua responden didapatkan hasil yang berbeda. Pada kasus I sudah berkurang sesak nafasnya pada hari ke 3 perawatan yang diikuti dengan perbaikan tanda-tanda vital yang mendekati rentang normal, dan keadaan umum yang semakin membaik, dan masalah intoleransi teratasi sebagian pada hari ke 3 perawatan.

\section{Referensi}

[1] Novarin, Christina, dkk. Pengaruh Progressive Muscle Relaxation terhadap Aliran Puncak Ekspirasi Klien dengan Asma Bronkhial di Poli Spesialis Paru B Rumah Sakit Paru Kabupaten Jember (The Effect of Progressive Muscle Relaxation on Peak Expiratory Flow Of Clients 
with Bronchial Asthma at Lung Specialist Unit B of Lung Hospital Jember Regency. Jurnal Pustaka Kesehatan, Vol. 3, No. 2. 2015.

[2] Tumigolong, Kumaat, Onibala. Hubungan Tingkat Kecemasan dengan Serangan Asma pada Penderita Asma di Kelurahan Mahakeret Barat dan Mahakeret Timur Kota Manado.Jurnal Keperawatan, Vol. 4, No 2. 2016.

[3] Clark, Margaret Varnell. Asma: Panduan Penatalaksanaan Klinis. Jakarta: EGC. 2016.

[4] Nursalam. Manajemen Keperawatan. Jakarta: Salemba Medika. 2016.

[5] Ross dan Wilson. Dasar-Dasar Anatomi dan Fisiologi. Edisi 12. Singapore: Elsevier. 2014.

[6] Nugroho, Y.A \& Kristiani, E.E..Batuk Efektif dalam Pengeluaran Dahak pada Pasien dengan Ketidakefektifan Bersihan Jalan Nafas di Instalasi Rehabilitasi Medik Rumah Sakit Baptis Kediri. Jurnal STIKES RS Baptis Kediri, Vol 4 (2): 135-142. 2011.

[7] Hasdianah. Patologi \& Patofisiologi Penyakit. Jakarta: Medical Book. 2016.

[8] Soemantri, Irman. Asuhan Keperawatan Pada Klien Dengan Gangguan Sistem Pernafasan. Edisi 2. Jakarta: Salemba Medika. 2012.

[9] Doengoes. Rencana Asuhan Keperawatan pedoman untuk Perencanaan Keperawatan Pasien.Edisi: 3. Jakarta: EGC. 2016.

[10] Clark, Margaret Varnell. Asma: Panduan Penatalaksanaan Klinis. Jakarta: EGC. 2016.

[11] Brunner, Suddarth. Keperawatan Medikal Bedah. Edisi 12. Jakarta: EGC. 2014. 